\title{
Von der Goltz Paşa'nın Osmanlı Askeri Okullarını Modernize Etmesi ve Türk İstiklal Savaşına Etkisi
}

\section{The Modernisation of Ottoman Military Schools by Von der Goltz Pasha and Its Impact on the Turkish National War of Independence}

\begin{abstract}
Nursel GÜLCÜ *
Öz: 18. yüzyılda askeri yenilgilerin artmasıyla birlikte devlet adamları ve tarihçiler, Osmanlı Devleti'nin içinde bulunduğu durumu ve ordunun zayıflamasını düzeltebilmek için Osmanlı Devleti'nin tüm kurumlarında ıslahat yapılmasını gündeme getirmişlerdir. Başlangıçta aksayan yerlerde iyileștirme şeklinde görülen sslahat hareketleri ilerleyen zamanlarda yenileşme, modernleşme ve batılılaşma çizgisinde devam etmiştir. İstanbul ve Berlin arasında, 1880 Mayıs'ından itibaren yoğun olarak sürdürülen görüşmeler sonunda Almanya, Colmar Freiherr Von der Goltz'u Osmanlı Devleti’ne göndermiştir. Goltz Paşa, kısa zamanda tuğgeneralliğe kadar yükselmiş, daha sonra Alman heyet başkanlığının yanında Osmanlı Genel Kurmay Başkan yardımcılığı görevini de üstlenmiştir. Goltz Paşa askeri kurumlar arasındaki hiyerarşinin bir düzene sokulmasının yanı sıra askeri okullarda okutulan dersler konusunda da önemli değişiklikler yapmıştır. Goltz Paşa'nın getirmiş olduğu geleneğin uzun yıllar muhafaza edilmesiyle beraber, daha sonraki süreçte Harbiye'de okuyan Cumhuriyetin kurucu kadrosu da Goltz’un Alman etkisinde modernleştirmeye çalıştığı askeri okullarda okumuşlardır. Türk-Alman ilişklerinin askeri alanını irdeleyen bu çaıı̧̧ma ile Osmanlı Ordusunun modernleşme dönemi ele alınmıştır. Dönemin resmi kaynakları, askeri salnameler ve o döneme ait araştırmalar incelenmiştir. Osmanlı ordusunun modernizasyonu için gerekli yenilikler Goltz Paşa tarafindan tespit edilmiş ve bu konularda raporlar hazırlanmıştır. Sonuçta askeri eğitim yeniden düzenlenmiş, rütbe sistemi ve askeri hiyerarşik düzen yeniden planlanmış fakat Osmanlı Devleti'nin I. Dünya Savaşı'ndan mağlup devletler arasından kurtulmasına engel olamamıştır.
\end{abstract}

Anahtar sözcükler: Osmanlı, Ordu, Goltz Paşa, Modernizasyon

\begin{abstract}
With the increase in military defeats in the $18^{\text {th }}$ century, statesmen and historians brought up the reform of all of the institutions of the Ottoman state in order to correct this situation and prevent the weakening of the army. Movements towards improvement, which were initially seen as improvement halted in places, but was continued along the lines of innovation, modernisation and westernisation. As a result of intensive negotiations between Istanbul and Berlin from May 1880, Germany sent Colmar Freiherr Von der Goltz to the Ottoman state. Goltz Pasha was promoted to brigadier general in a short time and subsequently became the head of the German delegation, as well as the Vice President of the Ottoman General Staff. Goltz Pasha made important changes in the teaching at military schools as well, in order to organize the hierarchy among military institutions. After the long tradition of Goltz Pasha, the founding staff of the Republic who studied at Harbiye also studied in the military schools that Goltz tried to modernise under German influence. This study examines the military field of Turkish-German relations and the modernisation period of the Ottoman Army. The official sources for the period, the Military Declarations and the research of that period were examined. The necessary innovations for the modernisation of the Ottoman Army were determined by Goltz Pasha and reports were prepared on these issues. As a result, military education was reorganised, the rank system and the military hierarchical order were re-planned, but these modernisations did not prevent Ottoman defeat in World War I.
\end{abstract}

Keywords: Ottoman, Army, Goltz Pasha, Modernisation

\footnotetext{
* Dr. Öğr. Üyesi, Akdeniz Üniversitesi, Eğitim Fakültesi, Sınıf Eğitimi Bölümü, Antalya. nurselgulcu@akdeniz.edu.tr, https://orcid.org/0000-0002-4488-0252
} 


\section{Giriş}

Türk Alman ilişkilerinin başlangıcı XV. yüzyıla kadar gitmektedir (Önsoy 2004, 9). XVIII. yüzyıla kadar Almanlarla, Osmanlı Devleti arasında önemli bir gelişme kaydedilememiştir (Beydilli 1983, 13).

İki devlet arasındaki siyasi ilişkiler, Prusya Kralı II. Frederich'in Osmanlı Devleti'nden yardım istemesi ve ittifak teklif etmesi üzerine Osmanlı Devleti ile Prusya arasındaki ilişkiler yeni bir mahiyet kazanmıştır. Osmanlı Devleti ittifak teklifini hemen kabul etmemekle beraber 1761 Temmuz ayında Prusya ile bir dostluk ve ticaret antlaşması imzalamıştır (Uzunçarşılı 1983, 200). 31 Ocak 1790 tarihli Osmanlı Prusya ittifak Antlaşması, siyasi anlamda büyük önem taşımaktadır. Osmanlı Devleti'nin Hristiyan bir devletle yapmış olduğu ilk ittifak antlaşması olması önemlidir. Bu antlaşma ile ilişkiler Osmanlı ve Prusya açısından Hristiyan ve Müslüman bir devletle birlikte hareket etmenin ne gibi dini sakıncaları olup olmayacağ kaygılarının ötesine geçilmiştir (Beydilli 1984, 45).

18. yüzyıldan itibaren Osmanlı Devleti'nin savaş alanlarında eski gücünü ortaya koyamaması sadece askeri anlamda değil, eğitim, yönetim ve maliye alanlarında da kendisini göstermeye başlamıştır. Bu bozukluklara teşhis koyup çare önerenlerden Kâtip Çelebi (Düstur'ul Amel li Islah el Halel); Koçi Bey (Risaleler), Defterdar Sarı Mehmet Paşa (Nesayihu'l üzera ve'l ümera) gibi düşünürler, Osmanlı'nın eski gelenek ve düzeninin bozulduğunu ve kanunnamelerinin yozlaştırıldığını öne sürerek düzende ıslahata yönelmeyi savunmuşlardır (Yılmaz 2004, 7). 18. yüzyılın her büyük askeri yenilgisinden sonra devlet adamları ve tarihçileri, devletin içinde bulunduğu durumu ve ordunun zayıflamasını tartışmaya başlamıştır (Findley 1994, 38). Savaş meydanlarında alınan üst üste yenilgiler sebebiyle Osmanlı Devleti'nin kurumlarında 1slahat kavramı gündeme gelmiştir. Osmanlı Devleti'nin kurumlarındaki bozulmayla birlikte gelen 1slahat hareketleri, değişik adlarla devletin yıkılışına kadar devam etmiştir.

Başlangıçta, aksayan yerlerde iyileştirme şeklinde görülen islahat hareketleri, ilerleyen zamanlarda yenileşme, modernleşme ve batılılaşma çizgisinde devam etmiştir (Ortayl1 1977, 24). Osmanlı Devleti’nde ilk askeri yenileşme, başka deyişle, çağın gereklerine göre subay yetiştirme ve kullanma isteği bu dönemde ortaya çıkmıştır. Modern matematik ve fizik de askerlik sanatının çağa uydurulması amacıyla eğitime yavaş yavaş girmeye başlamıştır (Adıvar 1970, 163).

Fransa'nın Mısır'ı işgali, Osmanlı Devleti'nin düşmanı kendi gücüyle bertaraf edemeyeceği ve kendi mevcudiyetini uzun zaman devam ettiremeyeceği kanaatinin Avrupa'da doğmasına sebep oldu. Avrupa devletleriyle aradaki teknik ve bilimsel uçurumun oluşturduğu gerilemenin çaresi sadece Yeniçeri Ocağı'nın düzeltilmesi değildi. Bunun için ülkenin yönetim ve toplum işlerini yepyeni bir bakış açısıyla yeniden ele alınması gerekiyordu. Böyle bir girişimin gerekliliğini ilk kez gören II. Mahmut olmuştur (Çağatay 1995, 53).

II. Mahmut Dönemi'nde Osmanlı'nın askeri yapısı yeniden kurulmuştur denilebilir. II. Mahmut askeriyede olduğu gibi, eğitime de son derece önem vermiştir (Berkes 1978, 187). II. Mahmut'un eğitimle ilgili ilk ve en önemli girişimi, ilköğretimi zorunlu kılan ferman çıkarmasıdır (Turhan 1969, 229). II. Mahmut döneminde açılan rüşdiye okulları, toplumdaki eğitimli insanların oranını yükseltmek ve Mühendishane, Tıbbiye ve Harp okulları benzeri okullara öğrenci yetiştirmek amacıyla kurulmuştu (Ergin, 1977, 394). Tanzimatın ilanından sonra eğitim konuları daha bağımsız bir konu olarak görülmüş ve orta öğretim kurumlarına öğrenci hazırlayan okullar üzerinde durulmuştur (Akyüz 1982, 116-118).

Tanzimat Dönemi'nin sonuna gelindiğinde, Osmanlı eğitim sisteminin en alt kademesinde iptidailer ve sıbyan mektepleri vardı (Akyüz 1982, 116-118). Tanzimat'ın yönetim kesiminde meydana getirdiği değişme, daha çok orta öğretim düzeyindeki eğitimi değişme yönünde etkilemiştir (Tekeli 1980, 72).

Sultan II. Abdülhamit Dönemi’nde eğitim meselesi, 1876 Kanun-i Esasi ile ele alınmış ve 
Kanun-i Esasi'de yer alan Osmanlı efradının kâffesince tahsil-i maarifin birinci mertebesi mecburi olacak ve bunun derecatı ve teferruatı nizam-1 mahsus ile tayin k1lınacaktır" maddesi ile ilköğretim zorunlu hale getirilmiştir (Kodaman 1999, 28).

1877-78 Osmanlı-Rus Savaşı sonunda ortaya çıkan sorunlar ve savaşın içteki ve dıştaki etkilerinin azalmaya başlayınca eğitim alanındaki düzenlemelerle yeniden ilgilenilmeye başlanmıştır (Komisyon 1998, 366). Savaşın hemen ardından imzalanan Berlin Antlaşması, Osmanlı Devleti'ni çok zor durumda bırakırken beraberinde bir gerçeği de ortaya çıkarmıştı;; Kırım Savaşı (1853-1856) sonrası, Avrupa güçler dengesinin korunması amaciyla, Osmanlı Devleti'nin toprak bütünlügünü garanti altına alan İngiltere ve Fransa, bu tutumlarından kesin olarak vazgeçmiş görünüyorlard. Bunun üzerine tek başına ayakta kalabilecek gücü uzun süreden beri kaybettiğine inanan ve varlığını, Avrupa devletleri arasındaki dengeden yararlanarak sürdüren Osmanlı Devleti, Kırım Savaşı sonrası İngiltere ve Fransa'nın, toprak bütünlüğünü garanti altına alma fikrinden vazgeçmeleri üzerine siyasi olarak yalnız kalmış ve zorunlu olarak Almanya'ya yaklaşmıştır (Karal 1983, 78).

İstanbul ve Berlin arasında, 1880 Mayıs'ından itibaren yoğun olarak sürdürülen yazışma ve görüşmeler, 14 Temmuz 1880 'de bir sözleşme imzalanmasıyla neticelenmiştir. 14 Temmuz 1880 'de iki ülke heyetlerince imzalanan bir sözleşme uyarınca, Almanya Osmanlı Devleti'ne bir askeri heyet göndermeyi kabul ediyordu (Ortayl1 1983, 59).

General Kaehler başkanlığındaki Alman askeri heyetinin ordudaki modernizasyon görevi devam ederken, heyete yeni subayların dahil edilmesi gündeme geldi. Osmanlı Devleti, Almanya'dan talep ettiği son subay listesinde de mevcut olan askeri okullar için bir uzman talebini 1883 y1lında tekrarlayacaktır (Turan 2000, 146).

\section{Osmanlı Ordusunda Alman Colmar Freiherr Von der Goltz Paşa}

Goltz Paşa, 1861 yılında tahsilini tamamladıktan sonra 41 numaral1 5. Doğu Prusya Alayı'nda teğmen olarak ilk görevine başlar. 1870 yılında başlayan Almanya-Fransa savaşından önce 27 yaşında olan Goltz, kurmay subay sıfatıyla 2. Ordu Karargahı'na tayin olmuştur. Goltz Paşa, bu karargahta birçok önemli şahsiyetle birlikte çalışma fırsatı yakalamıştır. Albay V. Stiehle ve 1864-1866 seferlerinde, Almanya prensi ile karargahında görev yapmış olan Binbaşı Grof Hoesler ile aynı ortamda bulunmuştur.

1870 Savaşından sonra 1871'de yüzbaş1lığa yükselen Goltz, 1883 senesine kadar Genelkurmay Karargahı'nda şube müdürü ve Harp Akademisi'nde eğitmen olarak hizmet vermiştir. 15 Haziran 1883 'de yarbay olmuş ve zamanın politik ve askeri gerekliliği üzerine kendisinin Türkiye'ye gönderilmesi kararlaştırılmıştır. Öncelikle Osmanlı askeri okullarının yeniden teşkilatlandırılması konusunda çalışmalar yapması beklenmiştir. Osmanlı Devleti'nde bulunan Alman askeri misyonu başkanı General Kaehler'in 1885 'te ölümü üzerine bu heyetin başına geçmiştir (Ulus 1986, 74).

Kurmay Yarbay rütbesiyle Türkiye'ye gelen Goltz'un Osmanlı Ordusu'ndaki asli görevi Askeri Okullar Müfettişliği' dir. Goltz Paşa, kısa zaman içinde tuğgeneralliğe kadar yükselerek Osmanlı Askeri Okullar Genel Müfettişi olmuştur. 1885'te İstanbul'da bulunan ve Alman askeri heyetinin başkanı olan Kaehler Paşa'nın ölümü üzerine padişah tarafından bu göreve uygun görülen Goltz, bu göreve Kaehler'den daha üst yetkiler alarak geçmiştir. Heyet başkanlığının yanında Osmanlı Genel Kurmay Başkan Yardımcılığı görevini de üstlenmiştir. Böylelikle Osmanlı Devleti'nde 13 yıl sürecek Goltz devri başlamıştır. 20 Nisan 1895'te mareşalliğe kadar yükselen Goltz Paşa'nın Osmanlı ordusundaki misyonu Almanya'nın Osmanlı politikasının en önemli aşamasını oluşturmuştur (Wallach 1985, 45).

Goltz Paşa, kendisiyle yapılan üç yıllık kontratın Sultan Abdülhamit tarafından onaylanmasından sonra Askeri Okullar Müfettişi sıfatıyla Osmanlı Devleti'nde resmen göreve başladı. Goltz Paşa'nın beraberinde Almanca, Fransızca ve İngilizce bilen üç subay bulunmaktaydı. Bu 
kişiler, Abdullah Paşa, Tahir Bey ve Reşit Bey idi. Goltz Paşa, göreve başladığında Harbiye Mektebi'nde okutulan derslerin subay yetiştirmekten çok uzak olduğunu tespit ederek öğrencilerin zihinlerinin gereksiz bilgilerle doldurulmasından vazgeçilmesini sağlayacak yeni metotlar geliştirdi (Kış 2017, 110).

Goltz Paşa'nın ilk önemli icraatı, askeri okullar ile ilgili layiha hazırlamasıydı. Goltz Paşa, kaleme aldığı layihada üç temel sorun üzerine odaklanmıştı. İlk planda, askeri okullarda okutulmakta olan ders sayılarının fazlalığı ve bununla birlikte askerlik mesleği ile doğrudan ilgili derslerin azlığı ve pratiklerinin eksikliğini sorun olarak ortaya koymuştur. İkinci olarak, askeri okullarda sabahleyin talim yapıldıktan sonra derslere başlandığı ve bundan dolayı yorgunluğun vermiş olduğu rehavetin derslerin verimini düşürdüğünü belirtmiştir. Bu sebeple öğrencilerin önce derslere ve daha sonra talimlere katılmasını tavsiye etmiştir. Son olarak, sabah derslerle sonra da talimlerle meşgul olan öğrencilere, özellikle sabah saatlerinde çay veya kahve verilmesini istemiştir. Askeri okulların modernizasyonu görevini yerine getiren Goltz Paşa, sadece eğitim ve öğretim konularında değil, subay terfilerinde de bazı düzenlemeler yapılması gerektiği konusunu gündeme getirmiştir. Bu konuda özellikle saray ile yakın ilişkiler içinde bulunan subayların kısa zaman diliminde hılı terfilerle üst rütbelere intibak ettirilmesi, ordu ve askeri okullarda istihdam edilen ve uzun süre atama ile taltif bekleyen diğer subayların hayal kırıklığına uğradıklarını ifade etmiştir (Kış 2017, 111-112). Goltz Paşa, teknik askeri bilgiden yoksun, rüşvet ve iltimas yoluyla yüksek mevkilere gelenlere açıkça karşı çıkmış ve orduda yüksek öğrenim görmüş erkan-1 harplerin daha kıdemli olması gerektiğini savunmuştur. Goltz Paşa'nın bu teklifi neticesinde 19. yüzyılın sonunda Askeri İdadi'yi bitirenlere mülazımlık, Harbiye Mektebi'ni bitirenlere yüzbaşılık ve Erkan-1 Harbiye'yi bitirenlere ise kolağası rütbesi verilmiştir (Ergin 1977, 888).

Goltz Paşa'nın Harbiye'de görev yaptığı dönemde askeri kurumlar arasındaki hiyerarşinin bir düzene sokulmasının yanı sıra askeri okullarda okutulan ders kitaplarının gözden geçirilerek eğitim programına dahil edilmelerinde birlik sağlanmaya çalışılmıştır. İlk aşamada, okutulan mevcut ders kitapları ile ilgili bir liste yaparak bunlar arasında bir düzenleme yapılmıştır. Programa dahil edilen yeni derslerle ilgili yabancı dilde bazı kitaplar temin edilmiştir. Bu derslere ait kitapların yabancı dilde yazılmış olmalarından dolayı bunların Türkçe'ye tercüme işlemi de Harbiye Mektebi'nde görevli hocalar vasıtasıyla gerçekleştirilmiştir (Kış 2017, 116).

Goltz Paşa, Harbiye Mektebi için yeni bir ders programı hazırladı. Bu programda, Almanya'daki Harbiye Mektebi'ni esas alarak, askerlikle ilgisi olmayan dersler müfredattan çıkarılıp yerine Harp Silah Araç ve Gereçleri, Harp Sanatı Tarihi, Osmanlı Askeri Teşkilat Tarihi, Yabancı Ülkelerin Teşkilatları gibi uygulamalı dersleri konuldu. (Wallach 1985, 54).

1888 yılında Harp Okulu'nda okutulan dersler ve öğretim kadrosu şu şekildedir:

$\begin{array}{ll}\text { Zeki Paşa } & \text { Askeri Okullar Nazırı } \\ \text { Goltz Paşa } & \text { Nazır Müsteşarı } \\ \text { Abdullah Efendi } & \text { Tercüman } \\ \text { Mirliva Legef Paşa } & \text { Şimendifer } \\ \text { Mirliva Osman Bey } & \text { Almanca } \\ \text { Mirliva Hafı Bey } & \text { Süvari } \\ \text { Erkan-1 Harp Kaymakam Şevki Bey } & \text { Tefazli } \\ \text { Erkan-1 Harp Miralay Şükrü Bey } & \text { Ders Nazırı } \\ \text { Erkan-1 Harp Miralay Ali Bey } & \text { Piyade Talimi } \\ \text { Erkan-1 Harp Kaymakam Galip Bey } & \text { Fransızca } \\ \text { Erkan-1 Harp Kaymakam Avni Bey } & \text { Heyet ve Takvim-i Arazi } \\ \text { Erkan-1 Harp Kaymakam H. Tahsin Bey } & \text { Lisan } \\ \text { Erkan-1 Harp Kaymakam Mustafa Bey } & \text { Lisan } \\ \text { Erkan-1 Harp Kaymakam İsmail Bey } & \text { Süvari Talimi }\end{array}$


Baytar Binbaşı Behçet Efendi

Erkan-1 Harp Binbaşı Mehmet Bey

Tabip Binbaşı Faik Efendi

Binbaşı Sadık Efendi

Binbaşı Hasan Efendi

Binbaşı Ali Rıza Bey

Binbaşı Hüseyin Fuat Bey

Binbaşı Ahmet Şakır

Erkan-1 Harp Kol Ağası Reşit Bey

Kolağası İbrahim Efendi

Yüzbaşı Refet

Binbaşı Hüseyin Efendi

Binbaşı İbrahim Efendi

Topçu Binbaşı Hayri Efendi

Erkan-1 Harp Yüzbaşı Halil Efendi

Erkan-1 Harp Yüzbaşı Sami Efendi

Erkan-ı Harp Yüzbaşı Cerfeski

Erkan-1 Harp Yüzbaşı Hadi

Erkan-1 Harp Yüzbaşı Haber

Erkan-1 Harp Yüzbaș1 Sami

Erkan-ı Harp Yüzbaşı Ali Rıza

Mülazım Faik

Erkan-1 Harp Yüzbaşı İzzet Efendi

Erkan-1 Harp Kolağası Ömer Suphi Bey
Fenn-i Ahval-i Fers

Silah Bilgisi

Sağlık Koruma

Piyade Talimi

Makine-i Aliyye

Handese-i Resmiye

Resim

Tarama

Mimari

Lisan Hocası Muavini

Kitabet

Hikmet ve Tatbikat

Handese-i Haliye

İstikamat-i Hafife Hocası Muavini

Topoğrafya Öğretmeni Muavini

Tabiye-i Husume

Rusça

Umumi Tefazli

Almanca

Almanca

Rusça

Meç

İstatistik ve Askeri Coğrafya

Tarih-i Killai (Kaleler Tarihi) ve Hizmet-I

Seferiyye (Salname-i Askeri, 1304(1888)

1888 yılında Harp Okulu'nda okutulan dersler ve öğretim kadroru değerlendirildiğinde; Goltz Paşa ile birlikte Harbiye'deki ders sayısının arttığı, Almanca hocalarının Harbiye'de ders vermeye başladığı görülmektedir. 1870 sayılı Askeri Salname ile dersler karşılaştırıldığında; 1870 tarihinde bir tane Fransızca hocası bulunurken, 1888 y1lında Harp Okulu'nda 1 tercüman, 1 Fransızca hocası, 3 Almanca hocası, 2 Rusça hocası ve 3 Lisan hocası bulunmaktadır. 1888 yılında ders sayısının arttığı, Silah Bilgisi, Sağlığı Koruma, Tefazli, Tarama, Mimari, Kitabet, Hikmet ve Tatbikat, Tabiye-i Husume, Handese-i Haliye, İstikamat-i Hafife, Heyet ve Takvim-i Arazi isimlerinde dersler konulmuştur. Bu derslerin daha çok uygulama ağırlıkta dersler olduğu dikkat çekmektedir (Salname-i Askeri, 1304 (1888).

Türkiye Cumhuriyeti'nin kurucusu Mustafa Kemal de 1899-1902 yıllarında Harp Okulu'nda okumuştur. Harp Okulu'nu sekizinci olarak bitiren Mustafa Kemal'in unutamadığı ve kendisinin yetişmesinde etkili olduklarına inandığı hocaları vardır. Fransızca öğretmeni Necip Asım Bey, Talim öğretmeni Rahmi Paşa ve muavinleri Binbaşı Fazıl Bey, Yüzbaşı Naci Bey’in Atatürk üzerindeki etkisi ölünceye devam etmiştir denilebilir. Naci Bey yıllar sonra kolordu komutanıyken Atatürk'ü ziyaret etmiş ve Atatürk kendisine büyük ilgi göstererek; yanında bulunan sınıf arkadaşı Ali Fuat Cebesoy'a dönerek 'Naci Paşa Hazretlerinin ikimizin üzerinde de emeği vardır" demiştir (Cebesoy 1966, 31).

II. Meşrutiyet'e kadar Harp Okulu'nda nazarı bilgiden çok uygulamalı öğretime ve özellikle tatbikatlara ağırlık verilmiştir. II. Meşrutiyet'in ilanı ile birlikte taşradaki harp okulları dağıtılırken, İstanbul'daki de daha iyi kontrol edilebilecek bir konuma getirilmiştir.

Balkan savaşları ve I. Dünya Savaşı'nın da çıkması okulun olduğu gibi öğretim kadrolarının da dağılmasına sebep olmuştur (Köksal 2007, 107).

I. Dünya Savaşı ile birlikte Harbiye'deki kadronun dağılmasına rağmen, Osmanlı Devleti I. 
Dünya Savaşı'na Almanya ile müttefik olarak girmiştir. I. Dünya Savaşı sonunda yenilen taraflar olarak kendi sorunlarıyla baş başa kalmalarına rağmen, savaş sırasında kurulan yakın ilişkilerin hemen bitmesi de söz konusu olamazdı. Osmanlı Devleti'nin önde gelen yöneticileri Enver, Cemal ve Talat Paşalar, Mondros Mütarekesi'nin imzalanmasından kısa süre sonra Almanya'ya gitmişlerdir. Ayrıca Osmanlı Devleti'nde görev almış subayların da mütareke sonrası Almanya'ya dönmeleri de zaman almıştır. İki ülke arasındaki uzun ve yoğun ilişkilerin bir anda kopma noktasına gelmesinde, savaş sonrası yoğun iç ve dış sorunların Almanya ve Osmanlı Devleti arasındaki ilişkileri zayıflatmış olduğu söylenebilir (Koçak 1991, 1-2).

\section{Sonuç}

Kökeni 15. yüzyıla kadar giden Osmanlı-Alman ilişkileri, 18. yüzyılda yapmış olduğu Osmanl1Prusya İttifak Antlaşmasıyla yeni bir nitelik kazanmıştır.

Osmanlı Devleti'nin 18. yüzyıldan itibaren savaş meydanlarında aldığı yenilgiler, eski gücünü kaybetmesine yol açmıştır. Başlangıçta sadece aksayan yerlerde iyileşme şeklinde düşünülen 1slahat hareketlerinin zamanla daha geniş kapsamlı bir harekete dönüşmesiyle modernleşme süreci başlayarak, Osmanlı Devleti batılılaşma yönünde adımlar atmaya başlayacaktır.

II. Mahmut döneminde ülkenin ve toplumun işleri yeni bir bakış açısıyla ele alınarak sadece askeri alanda değil, eğitim alanında da önemli çalışmalar yapılarak kanunlar çıkarılacaktır. II. Mahmut döneminde rüştiye okullarıyla beraber mühendishane, tıbbiye, harp okulları ve benzeri okulların açılmasıyla toplumdaki eğitimli insanların sayısının arttırılması hedeflenmiştir.

II. Abdülhamit döneminde eğitimin Kanun-i Esasi ile ele alınması ve ilköğretimin zorunlu hale getirilmesi, eğitimle ilgili önemli adımlardır. 1877-78 Osmanlı- Rus savaşı ve getirmiş olduğu sorunlar, eğitimle ilgili çalışmaları aksatmış olsa da bir süre sonra eğitimle yeniden ilgilenilecektir. Berlin antlaşmasıyla Osmanlı Devleti'nin toprak bütünlügünü garanti altına alan İngiltere ve Fransa'nın bu politikasından vazgeçtiği gerçeğini ortaya çıkardı. Osmanlı Devleti'nin siyasi olarak yalnız kalması ise Almanya ile yakınlaşmayı beraberinde getirecektir.

Osmanlı Devleti'nin ordusundaki modernizasyon konusunda Almanya' dan subay talep etmesiyle başlayan süreç, yeni subay listesi talepleriyle devam edecektir.

Goltz Paşa'nın Almanya'nın yardım talebine verdiği karşılık olarak yapılan 3 yıllık kontrat çerçevesinde Osmanlı Devletin de görev yapması mareşalliğe kadar yükselerek 13 yıl sürecek Goltz devrini başlatmış olacaktır. Goltz Paşa'nın Osmanlı ordusundaki misyonu Almanya ile Osmanlı Devleti arasındaki politikanın en önemli kısımlarından birini oluşturacaktır.

Goltz Paşa'nın askeri okulların modernizasyonunda sadece eğitim kurumlarında değil birçok askeri konuda yapılması gereken düzenlemeleri içeren raporlarla birçok soruna dikkat çekmiştir. Goltz Paşa'nın Harbiye Mektebi için yeni ders programı hazırlaması, uygulamalı dersler koyması ile bir nevi Almanya'da ki Harp Mektebini örnek aldığı söylenebilir. Goltz Paşa ile sadece ders sayısının artmadığı, aynı zamanda Alman hocaların da Harbiye'de ders vermeye başlaması, Alman etkisini Harbiye'de doğal olarak artırmıştır. 1888 (1304) Tarihli Askeri Salnamenin verdiği bilgiler çerçevesinde hoca sayısı ve derslere bakıldığında artan ders sayısıyla birlikte Almanca derslerinin de arttığı açıkça görülmektedir.

Sonuç olarak Goltz Paşa ile Osmanlı Devleti'nde Almanya etkisiyle beraber Harbiye'de birçok ders çeşidinin uygulama ağırlıklı olarak arttığı söylenebilir. Goltz Paşa'nın getirmiş olduğu geleneğin uzun yıllar muhafaza edilmesiyle beraber, daha sonraki süreçte Harbiye'de okuyan Mustafa Kemal Atatürk ve Cumhuriyetin kurucu kadrosu da Goltz 'un Alman etkisinde modernleştirmeye çalıştığı askeri okullarda okumuşlardır.

\section{Yazar notu}

III. Türk-Alman İlişkileri Sempozyumunda özet bildiri olarak sunulan bu makale, bildirinin genişletilmiş halidir. 


\section{KAYNAKÇA}

Adıvar A. (1970). Osmanlı Türklerinde ilim. İstanbul 1970.

Akyüz Y. (1982). Türk Eğitim Tarihi, Başlangıçtan 1982'ye. Ankara 1982.

Berkes N. (1978). Türkiye'de Çağdaşlaşma, İstanbul 1978.

Beydilli K. (1983). 18. Yüzyllda Osmanlı-Prusya Münasebetleri. İstanbul 1983.

Beydilli K. (1984). 1790 Osmanlı-Prusya İttifakl, Meydana Gelişi, Tahlili, Tatbiki. İstanbul 1984.

Cebesoy A. F. (1966). Sınıf Arkadaşım Atatürk. İstanbul 1966.

Çağatay N. (1995). “Tanzimat ve Türk Eğitim Sistemi”. Mustafa Reşit Paşa ve Dönemi Semineri (1995) 53-65. Ankara.

Ergin O. (1977). Türk Maarif Tarihi. İstanbul 1977.

Findley C. (1994). Osmanlı Devleti'nde Bürokratik Reform. İstanbul 1994.

Karal E. Z. (1983). Osmanlı Tarihi. Ankara 1983.

Kış S. (2017). Osmanl Ordusunda Alman Ekolü; Von Der Goltz Paşa (1883-1895). Konya 2017.

Koçak C. (1991). Türk-Alman Illişkileri (1923-1939). Ankara 1991.

Kodaman B. (1999). Abdülhamit Devri Eğitim Sistemi. Ankara 1999.

Komisyon (1998). Osmanlı Devleti ve Medeniyet Tarihi, İstanbul 1998.

Köksal N. (2007). Osmanl Devleti'nde Modernleşme Dönemi Askeri Eğitim Sistemi (1840-1908). Yayımlanmamış Yüksek Lisans Tezi. Kırıkkale Üniversiyesi, Kırıkkale 2007.

Ortaylı İ. (1977). Imparatorluğun En Uzun Yüzyllı. İstanbul 1977.

Ortaylı İ. (1983). Osmanlı İmparatorluğunda Alman Nüfuzu. İstanbul 1983.

Önsoy R. (2004). Türkiye’deki Almanya 1914-1918. Ankara 2004.

Salname-i Askeri. 1286 (1870). İstanbul 1870.

Salname-i Askeri. 1304 (1888). İstanbul 1888.

Tekeli İ. (1980). Toplumsal Dönüşüm ve Eğitim Tarihi Üzerine Konuşmalar. Ankara 1980.

Turan K. (2000). Türk Alman Eğitim ilişkilerinin Tarihi Gelişimi. İstanbul 2000.

Turhan M. (1969). Kültür Değişsmeleri, Sosyal Psikoloji Bakımından Bir Tetkik. İstanbul 1969.

Ulus İ. (1986). Colmer Freiherr Von Der Goltz'un Biyografisi. Ankara 1986.

Uzunçarşılı İ. H. (1983). Osmanlı Tarihi. Ankara 1983.

Wallach J. L. (1985). Bir Askeri Yardımın Anatomisi, Türkiye'de Prusya-Alman Askeri Heyetleri 18351999. Ankara 1985.

Yılmaz F. (2004). Imparatorluk Döneminde Türk-Alman İlişkileri. Ankara 2004. 
